\title{
REVIEWS
}

Some Game Birds of West Africa. By W. A. Fairbairn, E.D., D.Sc. Edinburgh: Oliver and Boyd, 1952. pp. 92. $12 s .6 d$. net.

Intended as a field reference, this book could be useful to sportsmen and ornithologists alike. There is information on the habitat, foods, nesting, and general habits of some fifty forms of waterfowl, francolins, partridges, quail, guinea-fowl, bustards, snipe, sandgrouse, plovers and pigeons.

Periods for close seasons are recommended and there is a list-far too short and omitting the small insectivorous and the frugivorous species - of " birds which merit protection in West Africa".

Coloured plates by Mrs. P. M. Sumner accompany the text, but although we are told in the publisher's note that "each is illustrated in colour so as to make recognition a matter of ease", the reproduction of some is so poor that recognition is rendered quite difficult.

$$
\text { J. J. Y. }
$$

\section{ZOO CAVALCADE}

The Zoo Story. By L. R. Brightwell (Museum Press, 16s.).

Visitors to the Fellows' Restaurant at the London Zoo will have read the notice directing that " men's dress must include a jacket and buttoned-up shirt". This is a far cry from the years following 1843 when, on the Terrace, as Mr. Brightwell tells us : "Top hats were a matter of unwritten law and smoking ... was rigorously tabooed." The Zoo has changed, indeed, since it first opened its one gate in 1828. The Zoo Story is divided into decades and traces the gradual growth and expansion, with occasional setbacks, of the Zoological Society and the Menagerie. We see incidentally some colourful sidelights on the life and tastes of growing London. Celebrated figures in the Zoo's administration help to fill a varied canvas, side by side with a procession of animals many of whom achieved extraordinary popularity with the public.

The arrival of the first giraffes in 1836 must have been an intriguing sight. These four animals, Mr. Brightwell tells us, walked from Blackwall to Regent's Park accompanied by the Society's Secretary, a retinue of Nubians and Maltese keepers, and a detachment of the Metropolitan Police. It is amusing to read of the quantities of spotted fabrics displayed in shop 
windows for months after this event-and to compare this with the polar bear toys which appeared during the Brumas epoch.

This book is amusing and informative; it cannot fail to leave the reader with a feeling of friendliness towards the Zoo. It is marred by inaccuracies. For instance, the date of foundation of the Fauna Society is given as 1931, and the map at the end shows a bus running from the North Gate to Chalk Farm ; for this the tired visitor would wait in vain.

As usual, Mr. Brightwell has been successful with his illustrations which enliven the text of a thoroughly enjoyable book.

A. M. V. B. 